\title{
COMBINATION OF 2D SHEAR WAVE REFLECTION SEISMICS AND TRAVEL TIME ANALYSIS OF BOREHOLE GEOPHONE DATA FOR THE INVESTIGATION OF A SINKHOLE AREA
}

\author{
Saskia Tschache \\ Leibniz Institute for Applied Geophysics (LIAG), Stilleweg 2, Hannover, 30655, Germany, \\ saskia.tschache@liag-hannover.de
}

Sonja H. Wadas

Leibniz Institute for Applied Geophysics (LIAG), Stilleweg 2, Hannover, 30655, Germany, sonja.wadas@liag-hannover.de

Ulrich Polom

Leibniz Institute for Applied Geophysics (LIAG), Stilleweg 2, Hannover, 30655, Germany, ulrich.polom@liag-hannover.de

\section{Charlotte M. Krawczyk}

Helmholtz Centre Potsdam GFZ German Research Centre for Geosciences, Telegrafenberg, Potsdam, 14473, Germany, charlotte.krawczyk@gfz-potsdam.de; and Institute for Applied Geosciences, TU Berlin, Ernst-Reuter-Platz 1, Berlin, 10587, Germany

\begin{abstract}
In November 2010, a $30 \mathrm{~m}$ wide and $17 \mathrm{~m}$ deep sinkhole occurred in a residential area of Schmalkalden, Germany. Subsequent geoscientific investigations showed that the collapse was naturally caused by the dissolution of sulfates below $80 \mathrm{~m}$ depth. In 2012, the Thuringian State Institute for Environment and Geology (TLUG) established an early warning system including 3C borehole geophones deployed in $50 \mathrm{~m}$ depth around the backfilled sinkhole.
\end{abstract}

During the acquisition of two shallow 2D shear wave seismic profiles in the vicinity of the sinkhole, the signals generated by a micro-vibrator at the surface were additionally recorded by the four borehole geophones of the early warning system and a vertical seismic profiling (VSP) probe in a fifth borehole. Travel time analysis of the direct P-and S-wave arrivals enhances the understanding of wave propagation in the area. Seismic velocity anomalies are detected and related to the structural seismic images of the 2D profiles. In case of travel paths perpendicular to faults, the velocity is decreased, whereas the velocity of waves travelling parallel to the strike direction of faults is not significantly lowered.

The combination of receivers located at the surface recording reflected seismic waves and distributed downhole receivers recording direct waves, enables analyzing of seismic wave propagation and velocities in more detail and beyond 2D. Therefore, the experiment setup will be further extended in future. The presented method shows the potential to locate instable zones in a sinkhole area. In our further research we propose to evaluate the suitability of the method for the time lapse monitoring of changes in the seismic wave propagation, which could be related to subrosion processes.

\section{Introduction}

Early recognition of sinkhole hazard is an important and challenging topic. The approach of the joint project SIMULTAN (Sinkhole Instability: integrated MULTiscale monitoring and ANalysis) is the combination of multi-disciplinary methods across different scales. One major step which is addressed by the project is the detection of unknown critical zones. Another one is the monitoring of suspect zones.

The shear wave reflection seismic method enables highresolution imaging of the near-surface particularly in urban areas (Inazaki, 2004; Pugin et al., 2004; Polom et al., 2010; Krawczyk et al., 2013). This technique has already been applied with success in sinkhole related studies (Krawczyk et al., 2012; Wadas et al., 2016; Wadas et al., 2017). Krawczyk et al. (2012) propose 
a low shear wave velocity combined with a chaotic reflection pattern as an indicator for subrosion areas. Depression structures, strong scattering of seismic waves and discontinuous reflectors are further features in the seismic data that indicate leaching of soluble rocks in the subsurface (Wadas et al., 2016). The detailed mapping of the local fault and fracture system enhances the understanding of groundwater flow, which is a key factor of subrosion (Harrison et al., 2002; Closson \& Abou Karaki, 2009; Wadas et al., 2017). Tomographic studies using seismic waves in karst and subrosion areas were successfully applied to image zones of decreased P-wave velocity related to karstified fracture zones (McDowell et al., 1993; Karaman et al., 2004). The aim of our study is to combine high-resolution 2D shear wave reflection seismic imaging with a survey similar to multi-offset multi-azimuth VSP.

\section{Study Area}

The study area is located in Thuringia, Germany. In 2010, a circular $30 \mathrm{~m}$ wide and $17 \mathrm{~m}$ deep collapse sinkhole occurred in a residential area of the town Schmalkalden (Schmidt et al., 2013). Fortunately, nobody was harmed, but infrastructure and private property were damaged. The sinkhole was backfilled immediately to stabilize the sloping terrain. Subsequently, various investigations were conducted on behalf of the Thuringian State Institute for Environment and Geology (TLUG) to clarify the cause of the sinkhole and to evaluate further sinkhole hazard. These included drilling of 5 cored boreholes and 2D P-wave reflection and refraction seismics amongst others (Schmidt et al., 2013). As no evidence for a large man-made cavity could be found, a natural origin by subrosion of sulfate rocks was concluded being a sinkhole forming process known from neighboring areas (Schmidt et al., 2013).

Starting at depths of $80-90 \mathrm{~m}$, a $30-40 \mathrm{~m}$ thick layer consisting of gypsum, anhydrite, and claystone acts as subrosion horizon (Schmidt et al., 2013). It is overlain by a $15-25 \mathrm{~m}$ thick massive dolomitic limestone layer, which allows unnoticed cavity formation below, and sandstones and claystones of Permian and Quaternary age (Schmidt et al, 2013). Karstification of carbonate rocks is observed to be very low in the study area (Schmidt et al., 2013). The presence of a regional fault zone and intensive fracturing benefit the subrosion process (Figure 1; Schmidt et al., 2013; Wadas et al., 2017). In 2012, an early warning system was established.
It includes, amongst other elements, four 3-component (3C) borehole geophones deployed in $50 \mathrm{~m}$ depth in four shallow boreholes surrounding the backfilled sinkhole (Figure 1; Schmidt et al., 2013).

\section{Concept and Data Acquisition}

Two 2D reflection seismic profiles (Figure 1) with a length of $192 \mathrm{~m}$ (Profile 1) and $226 \mathrm{~m}$ (Profile 2) were acquired along streets during daytime in the vicinity of the backfilled sinkhole. During the acquisition of Profile 1, a VSP probe clamped in $30 \mathrm{~m}$ depth in borehole KB5 (Figure 1) recorded the arriving signals simultaneously. Due to a technical problem, it could not be used during the acquisition of Profile 2. The four $3 \mathrm{C}$ borehole geophones of the early warning system located in boreholes KB1-4 (Figure 1) recorded data continuously throughout the survey of both profiles. As seismic source, the electrodynamic micro-vibrator ELVIS 7 developed at LIAG was used in SH-wave mode

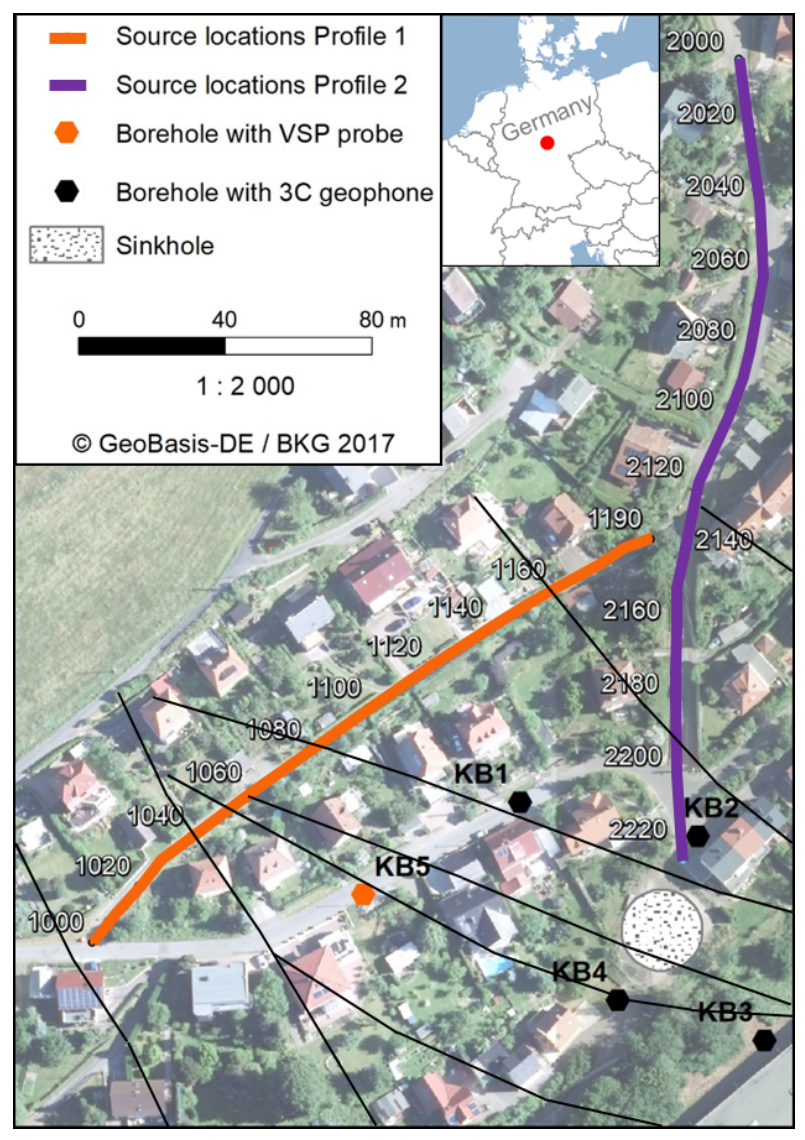

Figure 1. Location of profiles, boreholes and sinkhole in the study area Schmalkalden (red dot in map). Interpreted faults from previous seismic studies (Schmidt et al., 2013) are shown as black lines. 
(Polom, 2003; Druivenga et al., 2011). At each vibration point, two $20-120 \mathrm{~Hz}$ sweeps of opposing polarity were excited to suppress compressional wave energy on the SH-component records. The source point interval was $2 \mathrm{~m}$ and $4 \mathrm{~m}$ at the end of Profile 1 . For the two reflection seismic profiles, a land streamer developed at LIAG was used (Krawczyk et al., 2013). It is equipped with 120 1-component geophones in a $1 \mathrm{~m}$ spacing recording the SH-component. The VSP probe used consists of three geophone elements and the horizontal components can be oriented using an internal compass. In contrast, the orientation of the horizontal components of the permanently installed borehole geophones in $\mathrm{KB} 1-4$ is unknown. Another issue encountered is the time synchronization of all receivers. We achieved to determine exact shot times in an accuracy of $1 \mathrm{~ms}$ by simultaneous recording of GPS time signals during seismic data acquisition. However, the permanent borehole geophones of the early warning system (KB14) only use an internal time base, but no GPS sensor. Thus, the actual time difference between exact GPS time and the internal clock of the warning system is unknown and can only be roughly estimated.

Using the known distance between source and borehole sensor locations, an average velocity of the directly arriving $\mathrm{P}$ - or $\mathrm{S}$-wave is determined after picking of the arrival time. For calculation, a straight ray is assumed.

\section{Data Processing Reflection Seismic Data}

The reflection seismic datasets show a good data quality. In some shot gathers significant $50 \mathrm{~Hz}$ noise is observed due to power supply lines. An established shear wave processing flow similar to those described by Krawczyk et al. (2012) and Wadas et al. (2016) was applied. The first data processing steps comprised cross correlation of the raw vibration type data, trace editing, vertical stacking of shot records and a crooked line geometry setup. For noise suppression, a 20-25-90-100 Hz bandpass filter was applied and an individual notch frequency filter (e.g., $50 \mathrm{~Hz}$ ) to some of the shot gathers. An automatic gain control (AGC) with a $300 \mathrm{~ms}$ window was applied to the data of Profile 1. In case of Profile 2, an exponential gain of $\exp (2 t)$ yielded better results. Source noise dominant at near offset traces was reduced by FK filtering. After top muting and common midpoint (CMP) trace sorting, velocity analysis was performed in a $20 \mathrm{~m}$ interval. The stacking velocity field was iteratively enhanced by visual brute stack evaluation. Normal move-out correction and stacking was performed using the final velocity model. Subsequently, a finite difference time migration and FXdeconvolution were applied. The data were transformed to depth domain using a $1 \mathrm{D}$ velocity field. A CMPdependent static trace shift was applied to incorporate topography in the final seismic sections.

\section{VSP Probe Data}

The recordings of the VSP probe contain useful signal between source locations 1000 and 1144, which corresponds to a maximum travel path of $92 \mathrm{~m}$, but are heavily affected by crosstalk, especially the Y component. Due to the very similar behavior on all traces, it could be combated by subtraction of a bottom-muted average trace for every single component. The data processing comprised cross correlation with pilot sweep, component separation, vertical stacking, crosstalk noise suppression and bandpass filtering using a 15-20-55-60 Hz filter. The horizontal components were rotated towards the source based on the derived azimuth of the known source position, component orientation and a straight ray assumption for the travel path. First arrival energy is concentrated well on the Hmax component. Rotation of Hmax and $\mathrm{Z}$ components towards the source did not yield improved results so that first arrival picking was carried out on the Hmax component (Figure 2b). In seismic data acquired by vibration sources, the first arrivals are commonly located at the maximum of cross correlation of raw data and pilot sweep (Crawford et al., 1960). According to that, the first strong peaks were picked.

The travel time curve of the first break picks shows a linear alignment for the picks of an offset greater than $60 \mathrm{~m}$. The linear regression functions show a delay of the first arrivals of $85 \mathrm{~ms}$. This indicates that the picked arrival times are too late when assuming body waves propagating from source to receiver on a straight travel path with a velocity of $580-710 \mathrm{~m} / \mathrm{s}$ as indicated by the travel time curve slopes. It was not possible to pick consistent earlier arrival times which might also be caused by the strong crosstalk noise interfering the first $200 \mathrm{~ms}$ of the data. To concentrate on velocity differences along the profile rather than absolute velocities, a constant time shift of $-85 \mathrm{~ms}$ was applied to the first break picks (see also dashed line in Figure 2b).

\section{Continuous Borehole Geophone Data}

The first data processing steps involved extracting of the relevant parts of the continuous recordings and 

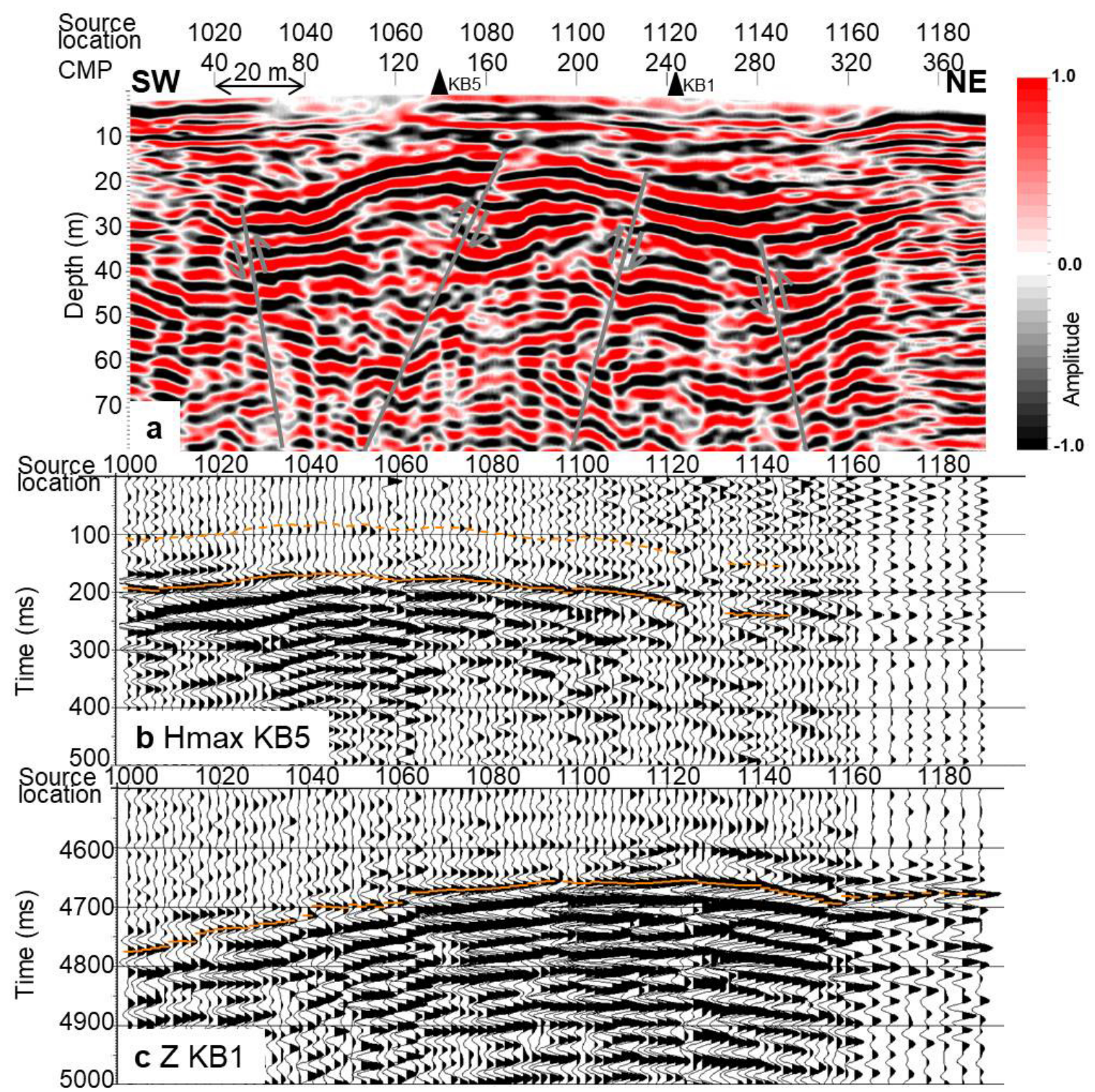

Figure 2. Seismic section of Profile 1 in depth below $327 \mathrm{~m}$ with interpreted faults. Borehole locations (full black triangles) are shown projected to the closest source location, respectively. (b) First arrivals (solid orange line) picked on the Hmax component measured in borehole KB5 and shifted $85 \mathrm{~ms}$ (dashed orange line). (c) First arrivals (solid orange line) picked on the Z component of the measurements in borehole KBI. Different time axes in b and c are due to time window used for extracting the data in c from continuous recordings.

conversion from MiniSEED to SEG-Y data format. We extracted $20 \mathrm{~s}$ long time windows starting $5 \mathrm{~s}$ before shot GPS time and assembled them in receiver gathers. Examination of the raw and cross correlated data revealed that, in case of Profile 1, only the geophone located in KB1 provided useful data and in case of Profile 2, the geophones in KB1 and KB2. The other borehole geophones are located too far away or are not sensitive enough to record the signals.

The raw data were cross correlated with the pilot sweep, vertically stacked and lowpass filtered with cutoff frequencies of 50 or $55 \mathrm{~Hz}$. Finally, a trace normalization was applied. First arrival times of source locations on 
Profile 1 were picked on the $\mathrm{Z}$ component data of the receiver in KB1 (Figure 2c). The signals of source locations 1160 and greater do not belong to a directly arriving body wave and these picks were excluded from further analysis.

At source locations 2172 and greater on Profile 2, the records of both receivers in $\mathrm{KB} 1$ and $\mathrm{KB} 2$ are dominated by a very strong ringing (Figure $3 b, c)$. The high amplitudes, early arrival times and travel time curve analyses indicate probably vibrations of the whole borehole casing excited by surface waves propagating along the sealed ground and hitting the top of the borehole. This behavior is consistently confined to the closest source locations and stops at source location 2172 for both receivers, although the ground conditions between source locations 2170 and 2172 do not show a visible difference.

First arrival times were picked between source locations 2012 and 2170 on the $\mathrm{Z}$ component of the receiver in $\mathrm{KB} 1$ (Figure 3b) and between source locations 2116 and 2170 on the Y component of the receiver in KB2 (Figure 3c).

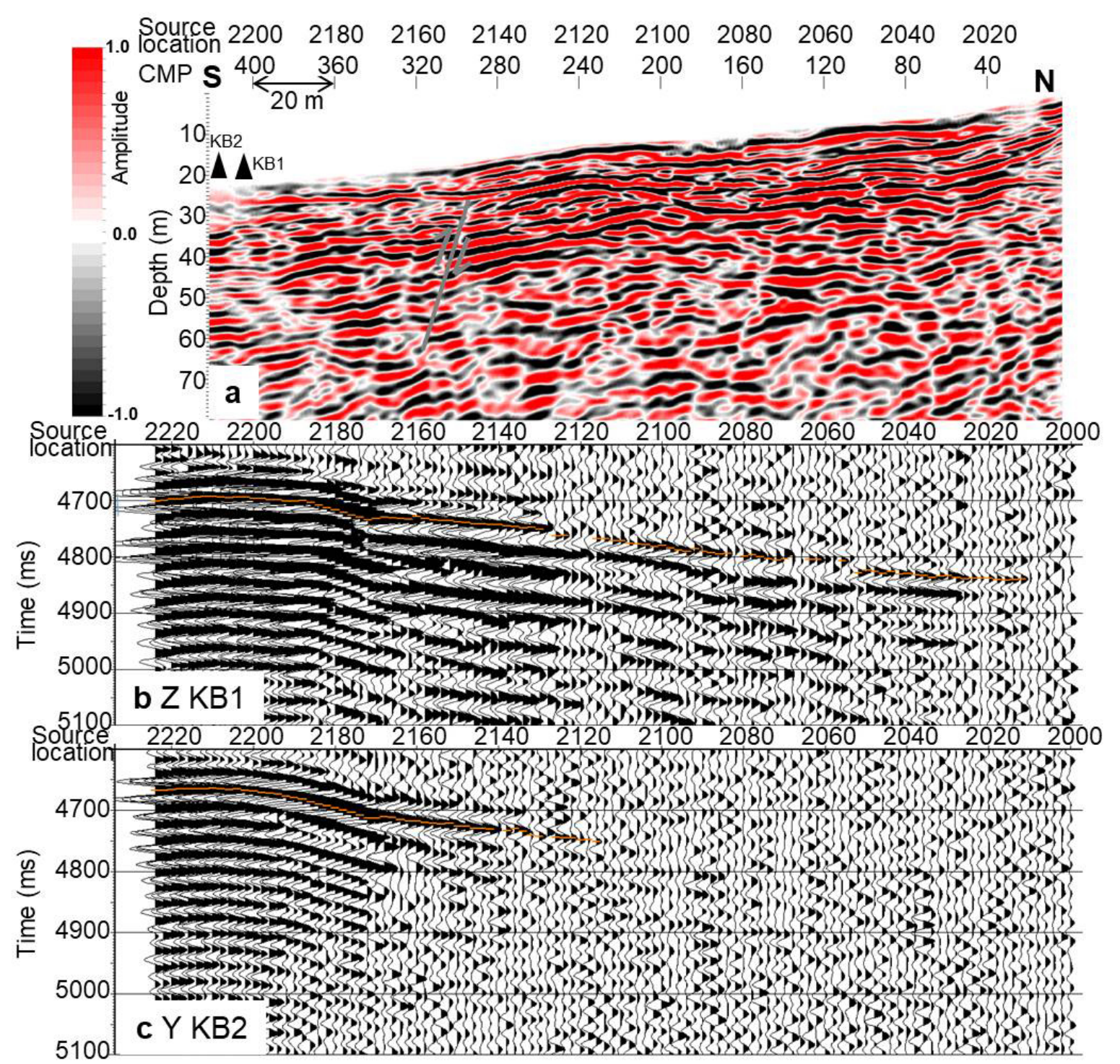

Figure 3. (a) Seismic section of Profile 2 in depth below $336 \mathrm{~m}$ with interpreted fault. Borehole locations (full black triangles) are shown projected to the closest source location, respectively. (b) First arrivals (orange line) picked on the Z component measured in borehole KB 1. (c) First arrivals (orange line) picked on the Y component of the measurements in borehole KB2. Note that only first arrivals of source location less than 2172 were used in the analysis of velocities. 
In travel time curves, the first arrival picks align very well to a linear function. The estimated shot time is $4670 \mathrm{~ms}$ (note that the time windows were cut $5 \mathrm{~s}$ before shot GPS time to allow for a clock difference of several seconds between GPS time and the internal time of the early warning system). As it cannot be derived with certainty, we assume a tolerance of $\pm 20 \mathrm{~ms}$ in the following. The influence of the picked phase and a typical period of 35$40 \mathrm{~ms}$ is one reason for uncertainty.

\section{Results and Discussion Profile 1}

The reflection seismic section of Profile 1 (Figure 2a) reveals a strong and undulating reflector at 20-30 m depth. With respect to borehole profiles of $\mathrm{KB} 1$ and KB5 (kindly provided by TLUG), we interpret this as a reflection between sandstone and claystone layers. Two depressions are shown between source locations 1020 and 1060 as well as between 1110 and 1170. Several faults can be interpreted. The reflections between $50-$ $70 \mathrm{~m}$ depth are less continuous and a strong fracturing is obviously present there.

The resulting velocities derived from the VSP probe data (orange dots in Figure 4) are between $700 \mathrm{~m} / \mathrm{s}$ and $800 \mathrm{~m} / \mathrm{s}$ for the western part of the profile (up to source location 1046 approx.), followed by a lowering of the velocity in the intermediate part and values of 500$600 \mathrm{~m} / \mathrm{s}$ in the eastern part (starting at source location 1060 approx.). A comparison with data of a later study, in which $\mathrm{P}$ - and S-waves were excited at the same location, confirmed that the observed first arrivals are most likely S-wave arrivals.
The velocities derived from the receiver in $\mathrm{KB} 1$ (blue dots in Figure 4) are between $500 \mathrm{~m} / \mathrm{s}$ and $700 \mathrm{~m} / \mathrm{s}$ and are interpreted as $\mathrm{S}$-wave velocities. The behavior of the S-wave velocity along the profile is different: medium velocities of $600-650 \mathrm{~m} / \mathrm{s}$ in the western part (up to source location 1062) and between source locations 1098 and 1126 , higher velocities of $650-700 \mathrm{~m} / \mathrm{s}$ between source locations 1064 and 1096, and low velocities below 600 $\mathrm{m} / \mathrm{s}$ in the eastern part (starting at source location 1130). This shows that the travel path and its direction affect the observed velocity. In general, we expect the average velocities derived from KB1 data to be slightly higher than those derived from KB5, because the borehole geophone in KB1 is located deeper and S-wave velocity tends to increase with depth. However, this is only observed for source locations 1058 to 1140.

Figure 5 shows the location of faults interpreted from the seismic sections shown here and further P- and S-wave reflection seismic studies (Schmidt et al., 2013; Wadas et al., 2017) and their dominant strike direction of NW-SE. We observe that travel paths parallel to the fault strike direction coincide with higher velocities and travel paths going through several faults more or less perpendicularly coincide with decreased velocities.

\section{Profile 2}

The reflection seismic section of Profile 2 (Figure 3a) shows strong reflections of the sandstone and claystone beddings in the uppermost $20 \mathrm{~m}$. In the southern part of the profile the reflection pattern is more chaotic than in the northern part. Indications of faults and fracturing are present.

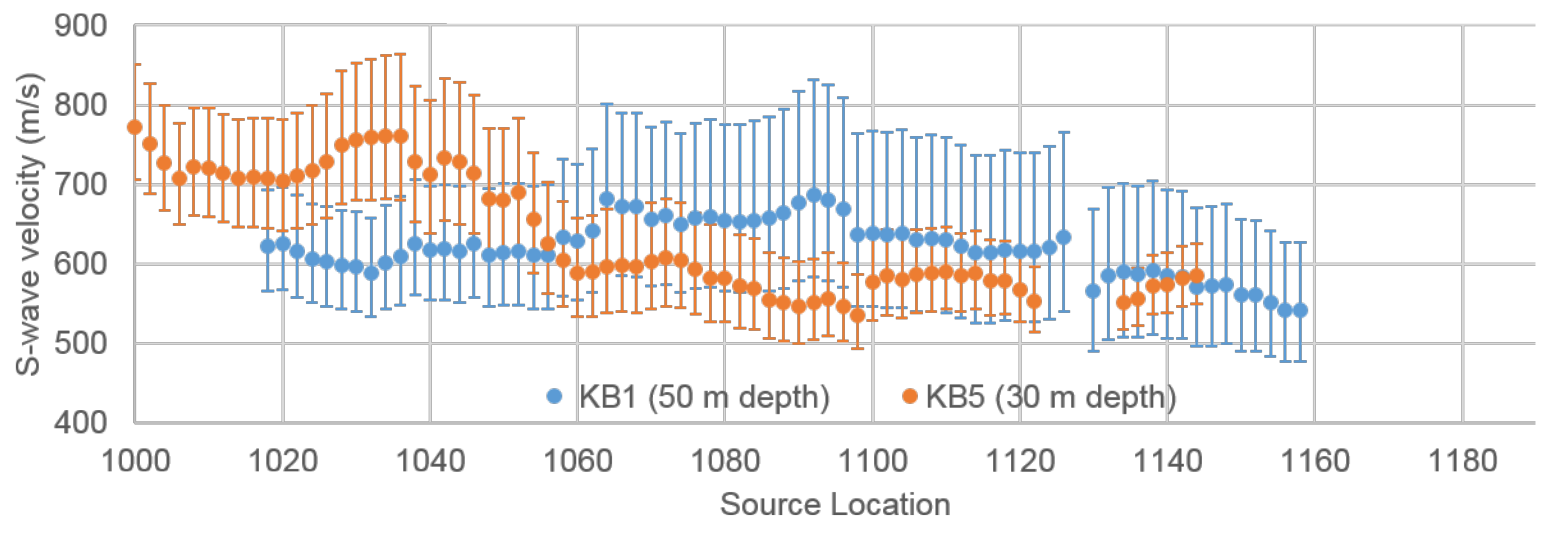

Figure 4. S-wave velocities derived from arrival times recorded by receivers in borehole KB 1 (blue) and KB5 (orange) during survey of Profile 1. Error bars shown correspond to estimated inaccuracy of derived shot time of KB 1-4 recordings (4670 $\pm 20 \mathrm{~ms})$ and estimated inaccuracy of time shift applied to arrival times of KB5 recordings ( $-85 \pm 10 \mathrm{~ms})$. 

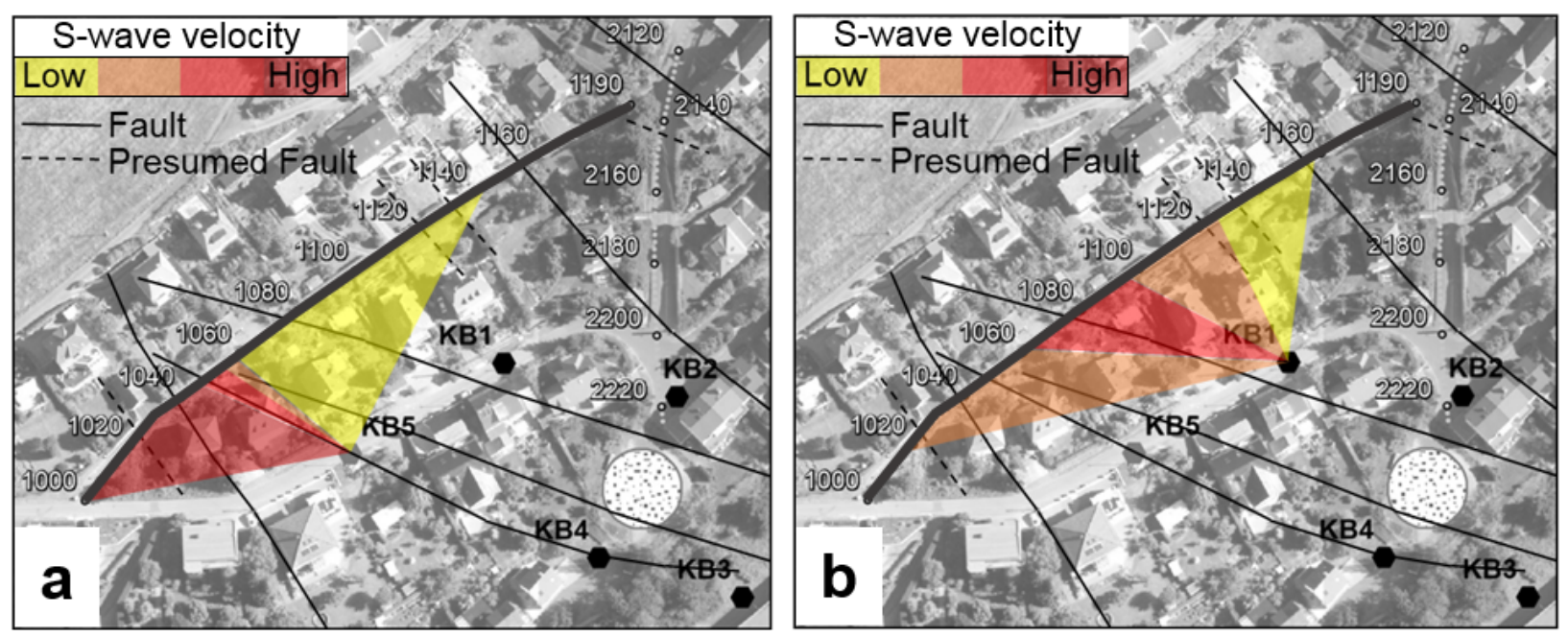

Figure 5. Section of the map shown in Figure 1. Solid lines mark faults interpreted in previous studies, dashed lines mark additional faults interpreted from seismic sections of this study. The colors indicate high and low average S-wave velocities observed using receivers in borehole KB5 (a) and KBI (b). For velocity values see Figure 4.

The observed average velocities for Profile 2 (Figure 6) are significantly higher compared to those of Profile 1. From this and the comparison with data of a later study, in which P- and S-waves were excited at the same location, we conclude that $\mathrm{P}$-wave first arrivals were picked. We assume that P-waves were directly generated at the source. The $\mathrm{P}$-wave velocities observed at the receiver in borehole KB1 range from $1100 \mathrm{~m} / \mathrm{s}$ to $1350 \mathrm{~m} / \mathrm{s}$ and do not show significant changes along the profile. Higher velocities are derived from data of the receiver in borehole KB2. This might be due to inaccuracy dependent on the phase of the wavelet used for picking. The southern part of the profile close to the sinkhole could not be included in the analysis due to strong interfering signals.

\section{Outlook}

At this stage, we did not try to invert for tomograms, as the ray coverage is too low. This could be a solution for future studies for improved localization and analysis of low velocity zones. In a subsequent study, we investigate subsurface velocities in more detail by distributing source locations throughout the whole study area and generating SH-, SV- and P-waves. Also, we propose to test the suitability of the described method for time lapse studies. The permanently installed borehole geophones enable a good repeatability and the quality of signal repeatability of the micro-vibrator source is usually high. In the past, offset VSP surveys were successfully applied for the detection of man-made fractures (Stewart et al., 1981; Hardage, 2000) by comparing data of transmitted waves acquired before and after fracturing. The authors

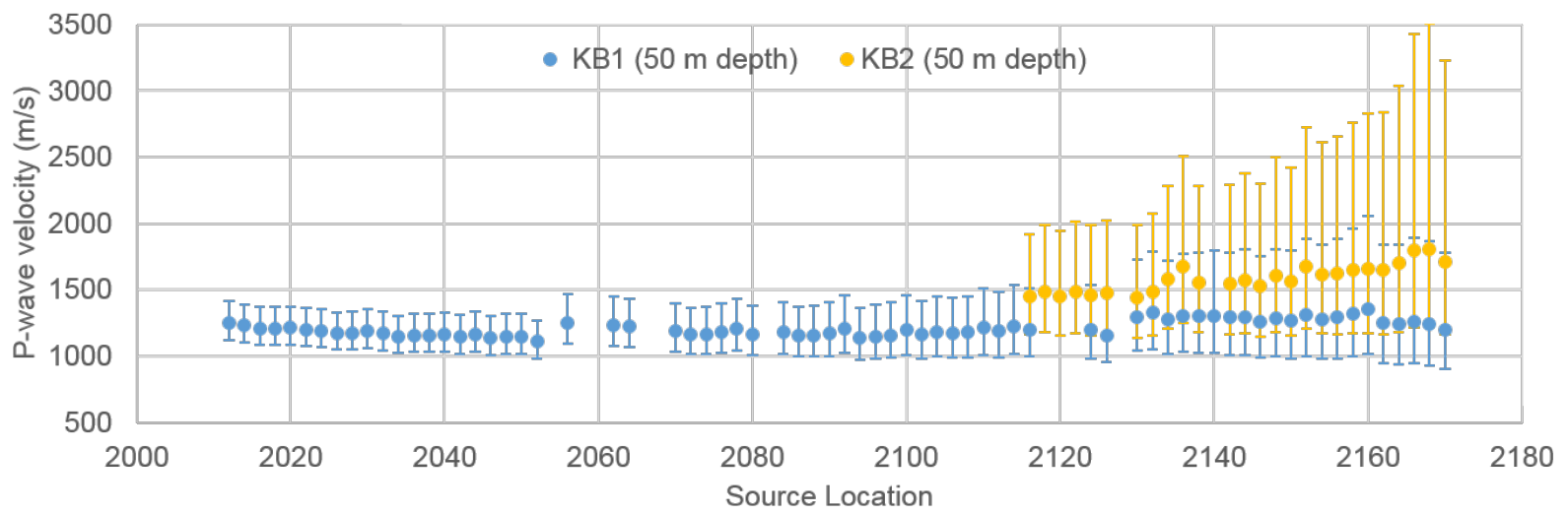

Figure 6. $P$-wave velocities derived from arrival times recorded by receivers in borehole KB 1 (blue) and KB2 (yellow) during survey of Profile 2. Error bars shown correspond to estimated inaccuracy of derived shot time of KB $1-4$ recordings (4670 $\pm 20 \mathrm{~ms})$. 
observed lowered propagation velocities, amplitude decay, increased scattering and change of S-wave polarization due to the man-made fracturing. This might also be an approach to monitor the evolution of natural fractures and cavities. However, it should be kept in mind, that, in the study area, all permanently installed borehole geophones are located above the actual subrosion horizon. Thus, with this setup it will only be possible to investigate indirect features of subrosion, e.g., increased fracturing on top of cavities, but not the dissolution of rock itself.

\section{Conclusions}

We achieved to analyze the velocity of directly arriving $\mathrm{P}$ - and S-waves at the borehole geophones closest to the source locations. Although the estimation of absolute velocities involves a remaining uncertainty due to unknown receiver clock difference and the influence of the wavelet phase used for picking of arrival times, the analysis of velocities along the profiles reveals that the average velocity from source to receiver location depends on the travel path and its direction towards the main fault strike direction. If travel paths are perpendicular to several faults, the average velocity is decreased. Travel paths parallel to fault strike directions are less affected resulting in higher average velocity. The described method enables the analysis of velocities in more detail and beyond $2 \mathrm{D}$. The combination of reflection seismic and travel time analysis of borehole sensor data enables to relate velocity anomalies to structural features. It is therefore a useful approach in near-surface and karst related investigations.

\section{Acknowledgements}

We would like to thank Erwin Wagner supporting data acquisition in the field, Britta Wawerzinek and Dirk Becker for support regarding raw data format conversion and Jan Bergmann Barrocas for creating the map in Figure 1. We thank the Thuringian State Institute for Environment and Geology (TLUG) for the permission to use components of its early warning system. The GIPP by GFZ German Research Centre for Geosciences provided free software for MiniSEED-SEG-Y format conversion.

This work is part of the joint project SIMULTAN funded by the German Federal Ministry of Education and Research under grant 03G0843A.

\section{References}

Closson D, Abou Karaki N. 2009. Salt karst and tectonics: sinkholes development along tension cracks between parallel strike-slip faults, Dead Sea, Jordan. Earth Surface Processes and Landforms 34: 1498-1421.

Crawford JM, Doty WEN, Milford RL. 1960. Continuous Signal Seismograph. Geophysics 25 (1): 95-105.

Druivenga G, Grossmann E, Grüneberg S, Polom U, Rode W. 2011. Transportabler Scherwellenvibrator. Deutsches Patent- und Markenamt, Offenlegungsschrift DE 10327757 B4.

Hardage B. 2000, editor. Vertical Seismic Profiling: Principles. 3rd ed. Oxford (UK): Elsevier Science Ltd.

Harrison RW, Newell WL, Necdet M. 2002. STRUCTURE AND GENESIS Karstification Along an Active Fault Zone in Cyprus. U.S. Geological Survey Water-Resources Investigations Report 02-4174; [cited 2017 September 25]. 5 p. Available from: https://water.usgs.gov/ogw/karst/ kig2002/pdffiles/rwh.wrir02-4174.pdf.

Inazaki T. 2004. High-resolution seismic reflection surveying at paved areas using an S-wave type land streamer. Exploration Geophysics 35: 1-6.

Karaman A, Karadayılar T. 2004. Identification of karst features using seismic P-wave tomography and resistivity anisotropy measurements. Environmental Geology 45 (7): 957-962.

Krawczyk CM, Polom U, Trabs S, Dahm T. 2012. Sinkholes in the city of Hamburg-New urban shear-wave reflection seismic system enables high-resolution imaging of subrosion structures. Journal of Applied Geophysics 78: 133-143.

Krawczyk CM, Polom U, Beilecke T. 2013. Shear-wave reflection seismics as a valuable tool for nearsurface urban applications. The Leading Edge 32 (3): 256-263.

McDowell P, Hope V. 1993. The location and delineation of karst and solution collapse features by acoustic tomography. In: Beck BF, editor. Applied karst geology. Rotterdam: AA Balkema, p. $123-129$.

Polom U. 2003. Schwingungserzeuger für seismische Anwendungen. Deutsches Patent- und Markenamt, Patentschrift Nr. 10235126 C1.

Polom U, Hansen L, Sauvin G, L'Heureux JS, Lecomte I, Krawczyk CM, Vanneste M, Longva O. 2010. 18. High-Resolution SH-Wave Seismic Reflection for Characterization of Onshore Ground Conditions in the Trondheim Harbor, Central 
Norway. In: Miller RD, Bradford JH, Holliger K, editors. Advances in Near-surface Seismology and Ground-penetrating Radar. SEG Geophysical Developments Series No. 15. p. 297-312.

Pugin AJM, Larson TH, Sargent SL, McBride JH, Bexfield CE. 2004. Near-surface mapping using $\mathrm{SH}$-wave and P-wave seismic land streamer data acquisition in Illinois, U.S. The Leading Edge 23 (7): 677-682.

Schmidt S, Wunderlich J, Peters A, Heinke O. 2013. Ingenieurgeologische Erkundung des Erdfalls vom 01. November 2010 am Rötbergrain in Schmalkalden und Beschreibung des Erdfallfrühwarnsystems in Schmalkalden. Report (unpublished). Thuringian State Institute for Environment and Geology. Jena, Germany.

Stewart RR, Turpening RM, Toksöz MN. 1981. Study of a subsurface fracture zone by vertical seismic profiling. Geophysical Research Letters 8 (11): 1132-1135.

Wadas SH, Polom U, Krawczyk CM. 2016. Highresolution shear-wave seismic reflection as tool to image near-surface subrosion structures - a case study in Bad Frankenhausen, Germany. Solid Earth 7: 1491-1508.

Wadas SH, Tanner DC, Polom U, Krawczyk CM. 2017. Structural analysis of S-wave seismics around an urban sinkhole: evidence of enhanced dissolution in a strike-slip fault zone. Natural Hazards and Earth System Sciences 17: 2335-2350. 
